\title{
Lecturas inadaptadas sobre los ciudadanos con dificultades sociales
}

\author{
Jaume Funes
}
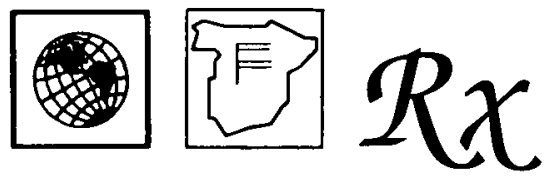

El artículo propone una pauta de análisis que ayude a evitar algunos de los problemas más frecuentes derivados de las respuestas y las intervenciones que la sociedad construye para afrontar las situaciones de marginación y de inadaptación social. Problemas tales como la patologización, la penalización, la protección y la burocratización.

Cada vez que he de ponerme a escribir sobre cómo se supone que es la infancia, la adolescencia y la juventud que llaman impropiamente «inadaptadas" —que deberíamos llamar marginadas, excluidas, con dificultades, en conflicto, etc.- encuentro en mi interior enormes reticencias a ejercer de psicólogo, a ponerme a mirar simplemente cómo son ellos y ellas por dentro. No puedo dejar de lado cómo son por fuera (cómo actúan, con quien se relacionan, en qué mundo viven). No puedo dejar de analizar las condiciones en las que crecieron y maduraron, ni la multiplicidad de respuestas que recibieron. No puedo dejar de lado que mas de un profesional me leerá en plan clínico y diseñará tratamientos para cada una de las «enfermedades sociales».

Para evitar todo eso - sobre todo cuando se trata de describir para actuarprefiero reflexionar de manera mas global, mas integradora y recordar algunos marcos de referencia que todos (educadores sociales, trabajadores sociales, terapeutas, ... a la postre todos educadores de lo social) deberíamos considerar. Las páginas que siguen son una reflexión crítica sobre donde nace la marginación, seguida de algunos recuerdos sobre las líneas globales que deberían presidir las intervenciones.

\section{RECORDEMOS ALGUNAS COSAS SOBRE MARGINACIÓN}

La marginación, la exclusión social, es producto, al menos de cuatro variables diferentes que, a su vez, nos hacen pensar en otras cuatro categorías, en otras cuatro grandes ideas asociadas a ellas.

\section{Sociedades inadecuadas}

Cada día se difunde mas en nuestra sociedad la idea según la cual la marginación es una cuestión de los individuos que nada tiene que ver son las sociedades con- 
cretas que la generan. Hablar de marginación supone hablar de inadecuación entre un colectivo, su entomo, sus reglas, y las características que tienen una serie de individuos. Cuando consideramos la marginación de las personas con discapacidades físicas precisamos que se trata de una inadecuación del espacio físico de la ciudad a su idiosincrasia. Igualmente, hemos de recordar la inadecuación cultural de la sociedad a las características culturales y vitales de las personas que tienen determinadas necesidades y dificultades sociales. No se puede hablar de política social pensando que una serie de técnicos sabios resolveremos los problemas de las sociedades que generan la marginación.

Podemos diseñar, planificar, aplicar un conjunto de medidas, pero siempre habremos de poner delante una frase mas o menos de este estilo: «todo eso, además de cambiar la sociedad». No se puede dejar de soñar en una sociedad diferente si se quiere hacer algún tipo de política contra la exclusión. Las sociedades inadecuadas nos conducen a pensar, de manera indefectible, en la justicia, en la igualdad, en la diversidad. No hay diseño posible de política social sin empatía social, sin una dosis mínima de utopía solidaria.

Nos estamos refiriendo, por lo tanto a sociedades no adecuadas para resolver las necesidades y las dificultades de determinadas personas. Desde la perspectiva positiva, pensamos en sociedades mas justas, mas permeables, mas accesibles.

\section{Construcciones problematizadoras de la dificultad}

Los llamados problemas sociales suelen tener más de construcción social que de realidad. Se sabe perfectamente cómo no es de recibo considerar que el principal problema de este país sea la drogadicción; sin embargo si se hacen encuestas «la droga» y el paro, el paro y la droga, forman el dúo alternativo de la prioridad en la preocupación de la gente. Hay una parte mucho mas importante de los problemas sociales vivida como real que problemas reales. Cuando se llega a convencer a la gente de que la calle es el reino del mal, del peligro, de los problemas, automáticamente tenemos un problema de marginación y de inseguridad. Nada nos dice que la calle sea más insegura, pero las personas la acaban viviendo como insegura.

En muchos de los problemas de marginación de adolescentes y jóvenes está presente la vivencia social construida ficticiamente, vivida como real, pero que no tiene nada que ver con el problema real. La reflexión desde esta perspectiva nos lleva así a distinguir los problemas reales y los problemas vividos como reales. Pero, sobre todo, al conocimiento de los chivos expiatorios, depositarios de la tensión social. No conozco ningún barrio que se queje de "la marginación social». Se sublevan porque dicen tener problemas de drogadictos y de inseguridad y, sin embargo, cualquier observador externo diría que lo que realmente tienen son problemas de degradación, de miseria, problemas de no encontrar ilusiones ni razones para vivir. Depositan en determinados problemas sus dificultades de agregación social.

\section{La reacciones incorrectas}

A menudo, sin embargo, la exclusión, la marginación es el producto de respuestas, de reacciones incorrectas ante determinados problemas sociales. Así, por ejemplo, decimos que es importante facilitar la reinserción social de las personas que salen de la prisión; pero, ¿ acaso no hemos creado una parte de la exclusión social utilizando la prisión como único sistema de respuesta penal ? ¿ Se pueda aceptar impasiblemente, por ejemplo, que en una población como la de España se haya pasado en seis años de tener 22.802 personas reclusas a las mas de 48.000 que existen en la actualidad ? ¿ Estamos haciendo un uso correcto de la reacción penal ?

Si se prefiere, podemos dejar a un lado la cuestión penal y abordar, por ejemplo, problemas de salud. $i$ Estamos seguros cuando hacemos campañas de preven- 
ción del sida de que, además de incitar al mantenimiento de conductas personales no transmisoras de la enfermedad, no estamos creando una serie de tensiones sociales que comportaran la marginación y la exclusión de los enfermos o los portadores? ¿Estamos contentos de que, por ejemplo, una serie de adolescentes reduzcan su probabilidad de contagio - algo que debe hacerse - sin pararnos a considerar que probablemente muchos de ellos estarán en el futuro neuróticos perdidos ? Es difícil vivir gozosamente las primeras relaciones sexuales amistosas entre adolescentes rodeándolas de fantasmas y de problemas complementarios como los que creamos indiscriminadamente con las respuestas al problema de salud creado por la aparición del sida.

Atención. Muchas veces las respuestas que damos a determinados problemas crean mas marginación que aquella que pretenden evitar. Hay mas problema con la reacción que con la dificultad inicial. El análisis de las respuestas nos lleva así a pensar especialmente en los cuatro tipos mas frecuentes:

* La patologización, la tendencia dominante entre muchos profesionales a considerar que los problemas de marginación son problemas de patología individual. Se propende con facilidad a convertir en enfermedades individuales aquello que es dificultad colectiva.

* La penalización, la tendencia a emplear el código penal como respuesta a todos los problemas sociales, sea cual sea su identidad. La respuesta que siempre tenemos preparada es la policía, los jueces y la cárcel.

* La protección, la tendencia a proteger a los débiles sin contar para nada con ellos, sin pararnos a modificar las circunstancias en las que se produce su desamparo. No puede aceptarse que proteger sea algo siempre bueno, que no cree a la corta un problema mayor. Resulta difícil aceptar, por ejemplo, que el gran número, en aumento, de menores hoy en día internados necesiten esa respuesta como la mas idónea y la necesiten por tan largo tiempo, sin que se aumente mas su marginación.

* La burocratización, la tendencia a dar respuestas formales, complicadas, sin ningún posicionamiento en la realidad de sufrimiento del otro. Somos capaces, por ejemplo, de retirar un menor de su familia porque sus padres no tienen posibilidades económicas de mantenerlo y exigir, a la vez, que acudan a repetidas visitas y entrevistas evaluadoras, gastándose en transportes y pérdidas de actividad de supervivencia el dinero que no tienen ni para el hijo. Da la impresión de que tan sólo pretendemos marearlos, sin confiar para nada en su posible recuperación.

\section{La circunstancias problemáticas}

Por supuesto, sería un reduccionismo olvidarse de que la marginación también nace de situaciones y circunstancias personales problematizadoras. Es obvio que también hay dificultades subjetivas, personas que padecen, que tienen problemas de salud, de salud mental, que se complican la vida de alguna manera, que pasan por situaciones de conflicto personal que les conducen a una situación de marginación.

La exclusión no puede ser considerada sólo como una categoría social, colectiva. Detrás de todas estas situaciones hay individuos, personas que padecen, que acumulan sus historias personales de dificultad capaces de desencadenar procesos de exclusión.

Pensar las políticas adecuadas tiene que llevar, también, a considerar el proceso individual de conversión en ciudadano, las relaciones mutuas que se establecen entre la persona y su comunidad, su grupo de referencia; a considerar, también, el proceso educativo y madurativo, a tener en cuenta la construcción de una vida saludable o el proceso individual de socialización.

Nada de lo que hemos considerado hasta ahora nos ahorra el observar, reflexionar y teorizar sobre el que supone vivir, crecer y madurar en condiciones difíciles. Si con la intervención educativa pretendemos compensar déficits, paliar padecimientos, estimular procesos de socialización, también habremos de descubrir cómo lo 
evolutivo se hace social, cómo lo social se hace evolutivo. De una manera resumida, mirándolo desde la infancia, diré que debemos considerar el impacto de cuatro grandes situaciones en las que parecen alterarse los mecanismos básicos de humanización:

a. La ausencia de un clima afectivo básico: nacer y crecer sin ser querido, estando de sobra, compartiendo el escaso afecto entre muchos, sintiéndose extraño y odiado, ...

b. Vivir en condiciones de desarrollo precarias: vivir en un entorno de escasos estímulos materiales, educativos, sociales, culturales, normativos, ...

c. Estar sometido a altas probabilidades de «siniestro»: vivir en un contexto familiar y social en el que fácilmente puedan verse afectados por acontecimientos traumáticos y problematizadores (vivir en un entorno delinquencial, de graves deterioro mentales, de estilos de vida marginales, etc.)

d. Socializarse rodeado de estímulos y modelos educativos negativos: adquirir identidades disociales, aculturaciones subculturales o degradadas, tener dificultades para comprender y dominar las normas, etc.

\section{DECÁLOGO PARA EL DISEÑO DE INTERVENCIONES SOBRE LA MARGINACIÓN}

Revisadas algunas de las situaciones generadoras de exclusión, me ha parecido que podía ser útil dedicar la segunda parte del artículo a recordar una propuesta básica sobre los criterios que deberían determinar hoy una política social contra la marginación. Una lista de criterios, de ejes centrales que habrían de ser respetados, si hemos de poner en marcha políticas que tengan en cuenta los procesos de marginación y exclusión social. De manera esquemática pueden resumirse en el siguiente decálogo:

Partir de acciones destinadas a reducir el contexto social injusto que provoca y mantiene la exclusión, así como actuar para compensar sus efectos

Aunque todos sabemos que la revolución pendiente ya se acabó, aunque desconfiemos seriamente de llegar a tener otro tipo de sociedad, no podemos - como personas que trabajamos en el campo social- quedarnos conformes ante una sociedad injusta. Hemos de hacer intervenciones sociales, pero a la vez recordar la injusticia; hacer patente que, marginada o no, hay gente que no come, hay personas que disponen de unos mínimos para sobrevivir. No se puede hacer política social contra la marginación si al menos algunos de sus elementos no son acciones de «choque», destinadas a reducir los efectos de la injusticia, a evitar que las personas marginadas se hundan cada vez más.

No pueden enviarse ejércitos de trabajadores sociales a un barrio degradado, sin recursos ni posibilidades de salir a flote. Son juegos florales si no insistimos en la necesidad de que se ejecuten acciones destinadas al menos a no agrandar cada vez mas las diferencias, los problemas, las injusticias, las desigualdades que provocan la situación de marginación. (Aquí pueden colocarse desde acciones mas complejas sobre el impulso socioeconómico de una comunidad, hasta las mas simples y cotidianas del salario de inserción social, del subsidio de desempleo, el salario social o las prestaciones mínimas para la supervivencia).

\section{Actuar desde el derecho a ser persona y no desde la amenaza de llegar a ser problema}

Se trata de un criterio que cada día parece más necesario recordar. La mayoría de los llamados programas destinados a prevenir la marginación están puestos en 
marcha basándose en el motivo de que, si no se actúa, algún día la gente será problema. La decisión nada tiene que ver con su derecho a llegar a ser personas. Tendría que estar prohibido hacer programas de prevención de la delincuencia, de prevención de la marginación. La gente de los barrios tiene derecho a crecer en condiciones correctas, no tiene derecho a no llegar a ser problema. No tenemos que hacer política social porque algún día tendremos problemas sociales. Hemos de hacer políticas contra la marginación porque las personas tienen derecho a incorporarse a la sociedad en condiciones razonables.

Ha de tenerse una cierta prevención (en el otro sentido de la palabra) hacia determinados conceptos, como el de «riesgo social». Los ciudadanos no tienen riesgos sociales, en todo caso viven en condiciones que les pueden provocar una situación de dificultad y marginación social.

\section{Trabajar las vivencias, las imágenes, las ideas colectivas que construyen y trasladan el problema mas allá de su realidad objetiva}

Si las prohibiciones no fueran inútiles y contraproducentes también me inclinaría por prohibir la utilización política de las miserias y dificultades humanas. Los responsables sociales habrían de ser honestos y explicar a la gente la realidad de los problemas que tiene no los problemas construidos. Sólo trabajando las vivencias que el ciudadano tiene, no aceptándolas como un dato inamovible, es posible actuar sobre los procesos de incorporación social. Resulta imposible convencer al ciudadano, por ejemplo, de la bondad de acoger adecuadamente en el barrio a una persona que tiene problemas de drogas, si antes lo hemos bombardeado con una serie de campañas sobre la peligrosidad de las drogas, si hemos etiquetado a la persona que tiene esos problemas como un ser abyecto, que no ha de estar ni en la calle, que ha de ser perseguido y acosado. ¿ Cómo le explicaremos después que es una persona humana a la que ha de incorporarse a la sociedad ?

Si no se reducen las vivencias, las construcciones sociales que hay detrás de los problemas, difícilmente se puede hacer política social.

Renunciar a la utilización de respuestas que generan mas marginación, a pesar de que tengan una rentabilidad política inmediata. (Sopesar la incidencia socializadora o dessocializadora de las medidas)

Se hace difícil aceptar que se pretenda la incorporación social cuando se afirman según que cosas sobre los jóvenes conflictivos o las personas que están en la cárcel. ¿ Cómo puede socializarse a una persona que además de estar en la cárcel, nada puede hacer parar variar su situación y, además, no puede acceder al exterior ni para preparar su regreso ? Medidas de ese tenor tienen una aparente rentabilidad política inmediata, pero hacen imposible cualquier diseño para ayudar a salir de la marginación.

A menudo se postula, sin más, la utilización dominante de medidas que provocan una fuerte dessocialización de las personas que están en situación de dificultad social.

Volver a creer en la intervención global, integrada, diseñando los mecanismos concretos que la hagan aplicable en las condiciones actuales

Quizás lo hemos olvidado, pero ya hace tiempo que decíamos aquello de que las personas son personas, es decir seres globales y no una suma de patologías. Por esa razón las políticas dirigidas a las personas han de ser globales, integrales, la atención 
no ha de consistir en un recorrido por múltiples ventanillas, por innumerables profesionales. Ha de volver a hablarse de la política social global, integral y, sobre todo, de cómo la podemos aplicar en este momento ya que una parte de la tendencia al desuso ha estado motivada por la dificultad de organización. Una parte de la renuncia a intentar políticas globales viene de su dificultad de aplicación en una administración compartimentada, cada vez mas palogizada por las respuestas concretas y específicas, así como para las batallas entre los diferentes niveles de competencias, sin especial preocupación porque las personas reciban una atención global y coherente.

La mayor parte de los programas específicos dirigidos a personas con dificultad social han nacido ya con el pecado original de crearles más segregación. En la actualidad, la mayor parte de las respuestas en el ámbito de juventud, en el penal, en el de la salud ... sólo son viables si son respuestas integradas dentro de la globalidad de las respuestas a los problemas que tiene las personas.

Hacer caer la centralidad de las acciones en la atención primaria sociosanitaria, redefinida y actualizada. Volver a los profesionales «inútiles». Evitar los inhabilitadores

La parte más esencial de la resolución de los problemas sociales sólo se puede lograr desde la atención primaria, entendida como la atención no especializada, como la atención directa a la persona, como la atención integrada. El adjetivo sociosanitaria lo he introducido expresamente por tratarse de un concepto clave dentro de la historia de la política social, que tiende a estar arrinconado y que debe ser recuperado. Sólo desde una atención primaria integrada en los aspectos sociales y sanitarios, añadiendo bastantes aspectos educativos, se puede hacer política de reducción de los problemas de exclusión social.

Además, de una manera similar a la que describía Illich, hemos tendido a llenar los programas de multiplicidad de profesionales especialistas con escasa capacidad de dar respuesta a los problemas reales de las personas', profesionales a menudo «inhabilitantes», creadores de etiquetas e identidades problemáticas.

Por el contrario ha de revitalizarse el peso que se otorga en las políticas contra la marginación, sobre todo en la infancia y la adolescencia, a los profesionales «inútiles». A aquellos profesionales que están allí donde están las personas, que conectan con la gente, que se mueven en su medio, no a los que están en los despachos estructurados y jerarquizados esperando que lleguen los "pacientes», identificados previamente con un problema, con una patología.

Profesionales cuya labor es aparentemente inútil. Educadores de calle, educadores, trabajadores sociales, profesionales que hacen intervención en un barrio desde encargos diversos pero que asumen su papel de «trabajadores de lo social», de personajes que hacen intervenciones que estimulan el proceso de socialización de las personas.

\section{Buscar la dimensión colectiva y comunitaria de las dificultades sociales. Volver a valorar el trabajo con la comunidad}

Aunque se trata también de un viejo concepto sobre el que se han escrito multiplicidad de páginas, algunas de ellas fuera de circulación, no se trata de un concepto que haya de caer en desuso. Si estamos hablando de las dificultades para incorporarse a la sociedad, a una determinada sociedad, estamos considerando un proceso de relación, una dinámica entre el individuo y la colectividad. Difícilmente se puede hablar de política social hacia la marginación sin una perspectiva comunitaria. No puede olvidarse que las dificultades sociales tienen que ver con contextos sociales concretos. 


\section{Diseñar acciones específicas para los colectivos en proceso intenso de socialización}

En el seno de los colectivos que tienen dificultad para incorporarse a la sociedad tienen mayores y mas específicas necesidades aquellos que están en la fase de transición hacia la vida adulta, hacia la sociedad adulta. De aquí la necesidad de insistir en los programas transversales que, por razón de edad, trabajan para que los adolescentes y jóvenes se incorporen a la sociedad sin dificultades ni conflictos. No podemos tener tan sólo — si existen-programas para jóvenes delincuentes. La tendencia a abandonarse las políticas de juventud (ante la preocupación por la tercera edad) puede dejarnos sin instrumentos para la socialización de los ciudadanos de menor edad. Hoy es exactamente igual de importante que hace cinco años el mantener programas de intervención sobre la adolescencia y la juventud para conseguir que su transición hacia la vida adulta sea socializada, no genere marginación y exclusión. No se ha acabado la época de las políticas de juventud y, dentro de las políticas de juventud, no ha pasado la época de los programas destinados a compensar sus dificultades de socialización.

Recuperar la dimensión territorial, el pueblo, el barrio, el polígono, etc. como contexto de intervención diferenciada

Hay que echarse a temblar, también, cada vez que se intentan poner en marcha programas genéricos contra la marginación para todo el Estado, o para toda Catalunya. Hace tiempo que sabemos que la dificultad social se produce en territorios concretos, en situaciones sociales concretas. Toda intervención social está ligada a un territorio, pero aquellas que tiene que ver con los procesos de socialización mucho más. Tanto la incorporación como el conflicto se producen en la interacción entre individuo, colectividad, territorio y momento social e histórico concretos.

Evitar discursos innecesarios y buscar respuestas a los problemas de la gente. Plantearse siempre la reducción de sus padecimientos

En alguna época nos hemos dedicado a hacer programas maravillosos que dejaban sin respuesta los problemas cotidianos de las personas marginadas. Cuando alguien sale de la cárcel no basta con que le facilitemos un programa de incorporación social; a menudo necesita comer y saber donde dormir y ese problema ha de tener una respuesta. Ello no quiere decir que haya de darse sólo esta última respuesta; esa atención ha de estar integrada en una más general e integradora. Suele pasar con frecuencia que damos maravillosas respuestas a problemas que la gente no tiene y los que tiene se quedan sin respuesta.

Al igual que planificamos con coherencia hemos de plantearnos cómo reducir los padecimientos, los sufrimientos de aquellos que se encuentran en situación de dificultad y conflicto social.

\section{Notas}

1 «... una época en la que la gente tenía problemas, los expertos tenían soluciones y los científicos median imponderables tales como capacidades y necesidades «. ILLICH, I., "Profesiones inhabilitantes". 


\section{Lecturas inadaptadas sobre los ciudadanos con dificultades sociales Jaume Funes CL\&E, 1995, 27, pp. 31-38}

Resumen: Comenzando por la propia palabra de inadaptación y siguiendo por la génesis de los procesos que conducen a colocar a una persona al margen de la sociedad, el artículo intenta aportar una pauta de análisis que permita elaborar adecuadamente las respuestas educativas. El contexto, las construcciones sociales, las reacciones y respuestas, así como las circunstancias personales problematizadoras, conforman un cuadro de desarrollo y maduración en el que se crea y conforma el adolescente o el joven disociales. Finalmente, el artículo propone un decálogo de criterios en los que enmarcar la programación y el diseño de recursos y servicios.

Datos sobre el autor: Jaume Funes Artiaga es psicólogo, educador y periodista. Se ha especializado a lo largo de su vida profesional en la atención a los adolescentes y jóvenes. Actualmente es docente, supervisor y consultor en las intervenciones y políticas que les afectan. Su último libro es «Mediación y Justicia juvenil».

Dirección: Diplomatura d'Educació Social. Fundació Pere Tarrés. Carolines 10. 08012 Barcelona. t. 4152551 .

(C) PERMISOS PARA CITAR O REPRODUCIR EN OTRAS FUENTES: Se pueden citar libremente hasta 500 palabras. Para reproducir una porción de texto mayor, figuras o ilustraciones, se deberá pedir permiso por escrito a la revista, especificando el uso al que se destina el texto. En todos los casos, se deberá citar el copyright de $C L \& E$. En el caso de artículos o textos que hayan sido a su vez reproducidos en $C L \& E$ los interesados deberán dirigirse tanto a los detentadores del copyright original como a $C L \& E$, en el caso de que se quiera hacer uso de la traducción. FOTOCOPIAS: Para todo lo relacionado con el uso mediante fotocopia del material de esta revista, deberán dirigirse a: CEDRO, C/ José Marañón, 10, $3 .^{\circ}$ Izda. Tel. 5941575 . Fax 4453567 